\title{
Dextran Sulfate Sodium-Induced Inflammation Is Enhanced by Intestinal Epithelial Cell Chemokine Expression in Mice
}

\author{
YOSHIKAZU OHTSUKA AND IAN R. SANDERSON \\ Department of Adult and Paediatric Gastroenterology, St. Bartholomew's and the Royal London School of \\ Medicine and Dentistry, London, U.K. [Y.O., I.R.S.]; Developmental Gastroenterology Laboratory, \\ Harvard Clinical Nutrition Research Center, Combined Program in Pediatric Gastroenterology and \\ Nutrition, Massachusetts General Hospital, Boston, Massachusetts 02129, U.S.A. [Y.O., I.R.S.]; and \\ Department of Pediatrics, Juntendo University School of Medicine, Tokyo, Japan [Y.O.]
}

\begin{abstract}
Dextran sulfate sodium (DSS) induces an inflammatory bowel disease-like colitis in animals. To determine the contribution of epithelium to inflammation in the intestine, we examined the effects of DSS in transgenic mice that specifically secrete macrophage inflammatory protein-2 (MIP-2) from the intestinal epithelium. We first confirmed the production of MIP-2 from intestinal epithelial cells by Western blots in transgenic mice. MIP-2 transgenic mice were therefore an appropriate model to examine the role of epithelial cell chemokines in an inflammatory state induced by DSS. We then examined the neutrophil migration into the intestine and the effect of DSS on this migration by myeloperoxidase staining. There was an increase of myeloperoxidase-positive neutrophils in the intestine from wild-type and transgenic mice after the DSS treatment. Furthermore, the increase of neutrophils under stimulation with DSS was confirmed quantitatively by measuring specific tissue myeloperoxidase activities. It was significantly greater in DSS-
\end{abstract}

\section{ABSTRACT}

treated MIP-2 transgenic mice than in wild-type mice in both the small intestine and colon. These results suggest that the inflammatory effects of DSS on both small intestine and colon are enhanced by MIP-2 secreted by epithelial cells in the transgenic mice. In conclusion, intestinal epithelial cells can act in concert with other inflammatory stimuli in maintaining inflammation. (Pediatr Res 53: 143-147, 2003)
Abbreviations
CMF-HBSS, $\mathrm{Ca}^{2+} / \mathrm{Mg}^{2+}$-free Hanks' balanced salt solution
DSS, dextran sulfate sodium
Fabpi, fatty acid binding protein of the intestine
IBD, inflammatory bowel disease
IEL, intraepithelial lymphocyte
MIP-2, macrophage inflammatory protein-2
MPO, myeloperoxidase

The intestinal epithelium regulates the absorption of nutrients and serves as a barrier to the external environment. Because the enterocyte is ideally placed to signal changes in the intestinal milieu through the expression of immunologically active proteins, it is also possible that epithelial cells are capable of signaling changes in the intestinal lumen to immune cells in the lamina propria or Peyer's patches $(1,2)$. Candidates for signaling include antigen presentation to mucosal $\mathrm{T}$ cells (3-6) and chemokine secretion (7-14). In vitro experiments

Received September 13, 2001; accepted June 20, 2002.

Correspondence: Ian R. Sanderson, M.D., Department of Adult and Paediatric Gastroenterology, Digestive Diseases Research Centre, The Royal London Hospital, Turner Street, London E1 2AD, U.K.; e-mail: i.r.sanderson@qmul.ac.uk

Supported by grants from NIH (AI43472, DK47753), the Medical Research Council, the Joint Research Board of St Bartholomew's Hospital, The Mercers' Company, and the Uehara Memorial Foundation, Tokyo, Japan.

DOI: 10.1203/01.PDR.0000041519.16507.06 have repeatedly demonstrated that epithelial cell lines respond to bacterial pathogens by secreting chemokines (9-12). Moreover, changes in normal intestinal contents vary the expression of chemokines by epithelial cells $(4,13,14)$. For example, butyrate, a short-chain fatty acid derived from the fermentation of nonabsorbed carbohydrate by intestinal bacteria, regulates the expression of MIP-2 in mouse and IL-8 in human intestinal epithelial cells. However, the contribution of the epithelium to inflammation established in the intestine is not clear. It is possible that when children with Crohn's disease receive enteral feedings (15), the changes in the intestinal lumen are detected by the epithelium and relayed to the mucosal immune system (16). To test the hypothesis that epithelial cell signaling influences the degree of inflammation established in the intestine, we compared the effects of DSS in normal mice with mice whose intestinal epithelial cells of the small intestine and proximal colon secrete MIP-2. The exact mechanism whereby DSS causes inflammation is not fully elucidated; however, it 
induces reproducible colitis in rodents $(17,18)$ and it is an established model of IBD.

MIP-2 is a member of the $\alpha$-chemokine family, which includes human IL-8 (which is not expressed in the mouse), human $\mathrm{GRO} \alpha$, rat $\mathrm{KC} / \mathrm{CINC}$, and murine $\mathrm{KC}$. As with IL- 8 in humans, MIP-2 is chemotactic for neutrophils and induces a localized neutrophil infiltration when injected into the hind footpads of mice (19-21). Therefore, MIP-2 acts in the mouse in a similar manner to IL-8 in humans. MIP-2 is only expressed in intestinal epithelial cells after stimulation with lipopolysaccharide or proinflammatory cytokines $(13,14)$. Since normal intestinal epithelial cells do not express MIP-2, inducing MIP-2 expression in the epithelium using transgenic techniques enabled us to study the effect of chemokine signaling by epithelial cells in the mucosal immune system in vivo. MIP-2 transgenic mice were generated by using an epithelial cellspecific promoter from the gene encoding Fabpi (22-24). Because the Fabpi promoter is specifically active only in the intestinal epithelium, MIP-2 is continuously expressed from intestinal epithelial cells in these mice but not in wild-type mice (25).

In this article, we investigate the interaction of intestinal epithelial cells with another chemical stimulus by administering DSS into both normal (wild-type) and MIP-2 transgenic mice, and discuss the role of intestinal epithelial cells in the mucosal inflammation.

\section{METHODS}

Mice. MIP-2 transgenic mice and wild-type mice aged 3 to 6 mo were used. MIP-2 transgenic mice were established using the plasmid containing the Fabpi promoter linked to the MIP-2 gene and the SV40 intron and polyadenylation site (Fig. 1). Because Fabpi is specifically expressed by intestinal epithelial cells, these mice express MIP-2 mRNA and produce MIP-2 from the intestinal epithelium without any stimulation (25). MIP-2 transgenic mice develop normally, with no diarrhea, and reveal no significant differences in body weight compared with wild-type mice. Some of both wild-type and transgenic mice were given 2.5\% DSS (Sigma Chemical Co., St. Louis, MO, U.S.A.) in drinking water for $10 \mathrm{~d}$ to induce intestinal inflammation $(17,18)$. Experiments were approved by the Subcom-

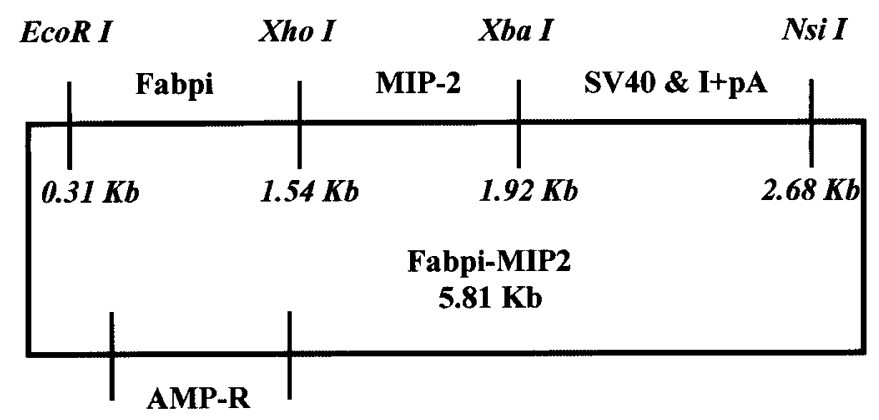

Figure 1. Generation of MIP-2 transgenic mice. Diagrammatic representation of the plasmid containing the Fabpi promoter linked to the MIP-2 gene and the SV40 intron and polyadenylation site. MIP-2 cDNA was derived from a mouse MIP-2 sequence using PCR with primers synthesized with an XhoI site and an $X b a$ I site. mittee on Research Animal Care of Massachusetts General Hospital, Boston MA, U.S.A., and by the Animals (scientific procedures) Act 1986, Home Office, London, U.K.

Epithelial cell preparations. Each intestinal sample was removed and flushed with CMF-HBSS (Sigma Chemical Co.), and all Peyer's patches were removed, before isolation of epithelial cells. The intestine was then opened longitudinally, washed gently with CMF-HBSS, and cut laterally into small pieces. Each segment was incubated in CMF-HBSS containing $1 \mathrm{mM}$ EDTA and stirred for $20 \mathrm{~min}$ four times to remove epithelium (26). Cell suspension was filtered through nylon mesh and centrifuged. The cell pellet, consisting of epithelial cells and IEL, was suspended in RPMI 1640 medium (Sigma Chemical Co.) containing 10\% FCS, $10 \mathrm{mM}$ L-glutamine, 0.05 $\mathrm{mM} 2$-mercaptoethanol, $100 \mathrm{U} / \mathrm{mL}$ penicillin, and $100 \mu \mathrm{g} / \mathrm{mL}$ streptomycin. Then IEL were removed from the epithelial cell suspension using a $45 \%$ to $70 \%$ discontinuous Percoll (Sigma Chemical Co.) gradient as previously described (26).

Cytoplasmic MIP-2 extraction and MIP-2 Western blot analysis. Epithelial cell membranes were ruptured with hypotonic buffer, containing $10 \mathrm{mM}$ HEPES, $10 \mathrm{mM} \mathrm{KCl}$, and 1.5 $\mathrm{mM} \mathrm{MgCl}{ }_{2}$, and the resulting cytoplasmic protein was extracted by centrifugation at $3300 \times g$ for $15 \mathrm{~min}$ at $4^{\circ} \mathrm{C}$. MIP-2 was detected on Western blot analysis as previously described (13). Samples were mixed $1: 2$ in $2 \times$ treatment buffer $(0.5 \mathrm{M}$ Tris- $\mathrm{HCl} / 4 \% \mathrm{SDS} / 20 \%$ glycerol $/ 10 \%$ 2-mercaptoethanol, $\mathrm{pH}$ 6.8) and heated in boiling water for $3 \mathrm{~min}$. Samples were loaded into an SDS/3.5\% polyacrylamide gel stacker over an SDS $15 \%$ polyacrylamide gel, and transferred to nitrocellulose membranes (Bio-Rad Laboratories, Richmond, CA, U.S.A.) for $90 \mathrm{~min}$ at $400 \mathrm{~mA}$ at $4{ }^{\circ} \mathrm{C}$. After blocking with $5 \%$ nonfat dry milk, nitrocellulose membranes were incubated with a goat anti-mouse MIP-2 antibody (Sigma Chemical Co.) at a 1:2000 dilution and stored overnight at $4^{\circ} \mathrm{C}$. After washing with PBS, membranes were incubated with a 1:8000 dilution of horseradish peroxidase-labeled rabbit anti-goat IgG (Sigma Chemical Co.). Epichemiluminescence detection reagents (Amersham International, Buckinghamshire, U.K.) were applied according to the manufacturer's instructions. Mouse recombinant MIP-2 (Sigma Chemical Co.) was used as a positive control.

Histologic analysis. Twenty-five milliliters of CMF-HBSS was perfused transcardially to flush all blood components from the intestinal vasculature. Intestine was then removed and washed gently with CMF-HBSS and snap-frozen in liquid $\mathrm{N}_{2}$. The neutrophil infiltration of the intestinal mucosa was examined by staining frozen sections $(4 \mu \mathrm{m})$ for MPO using the Hanker Yates reaction (27). Sections were incubated with Hanker Yates reagent (Sigma Chemical Co.), $1 \mathrm{mg} / \mathrm{mL}$ in 10 $\mathrm{mL}$ of $0.1 \mathrm{M}$ Tris buffer (pH 7.6) containing $1 \mu \mathrm{L} / \mathrm{mL}$ of $3 \%$ $\mathrm{H}_{2} \mathrm{O}_{2}$ for 30 min and counterstained with hematoxylin before examination by light microscopy.

Total MPO activity. For measurement of functional MPO activity, tissue specimens were weighed and homogenized in 5 $\mathrm{mL}$ of $50 \mathrm{mM}$ phosphate buffer $(\mathrm{pH} 6.0)$ at $4^{\circ} \mathrm{C}$, and centrifuged at $30,000 \times g$ for $30 \mathrm{~min}$ at $4^{\circ} \mathrm{C}$. The pellet was extracted with $0.5 \%$ hexadecyltrimethylammonium bromide (Sigma Chemical Co.) in $50 \mathrm{mM}$ phosphate buffer (pH 6.0) at $25^{\circ} \mathrm{C}$ 
(28). Samples were frozen on dry ice and sonicated. These were then centrifuged at $30,000 \times g$ for $30 \mathrm{~min}$. Supernatants were reacted with o-dianisidine dihydrochloride (Sigma Chemical Co.) containing $1 \mu \mathrm{L} / \mathrm{mL}$ of $3 \% \mathrm{H}_{2} \mathrm{O}_{2}$, and the $\mathrm{MPO}$ activity was assayed spectrophotometrically. Results are expressed per unit weight of intestine.

The thickness of the small intestine is greater than that of the colon, owing mainly to greater amounts of muscle and connective tissue. Expression of MPO activity as a proportion of unit weight of whole tissue appears, therefore, to be greater in colon samples than in small intestine. Nevertheless, this does not invalidate comparisons of similar organs between wildtype and transgenic mice. Each experiment was repeated three times with age-matched mice between 3 and 6 mo of age. Treatment groups consisted of eight mice.

Statistics. All data were analyzed by performing two-tailed, unpaired $t$ tests. A $p<0.05$ was considered significant.

\section{RESULTS}

Fabpi gene induces MIP-2 expression in epithelial cells in transgenic mice. Epithelial cells derived from wild-type mice accumulated no MIP-2 mRNA by either Northern blots or reverse transcriptase-PCR. However, both methods detected MIP-2 transcripts in the intestinal epithelium of MIP-2 transgenic mice (25). To confirm the production of MIP-2 from intestinal epithelial cells, epithelial cells were isolated and protein was extracted. The production of MIP-2 from intestinal epithelial cells was not detected extracellularly. However, MIP-2 protein was present in cytoplasmic lysates of epithelial cells from each MIP-2 transgenic mouse, whereas there was no MIP-2 observed in wild-type mice examined by Western blots (Fig. 2).

Production of MIP-2 by epithelial cells increases the inflammatory response caused by DSS. Because MIP-2 is known as a chemoattractant for neutrophils $(17,18)$, we examined whether the MIP-2 secreted by intestinal epithelial cells increased neutrophil recruitment in vivo. As previously demonstrated, there were few MPO-positive neutrophils in the small intestine and colon in wild-type mice. However, MPOpositive neutrophils were increased in the lamina propria of

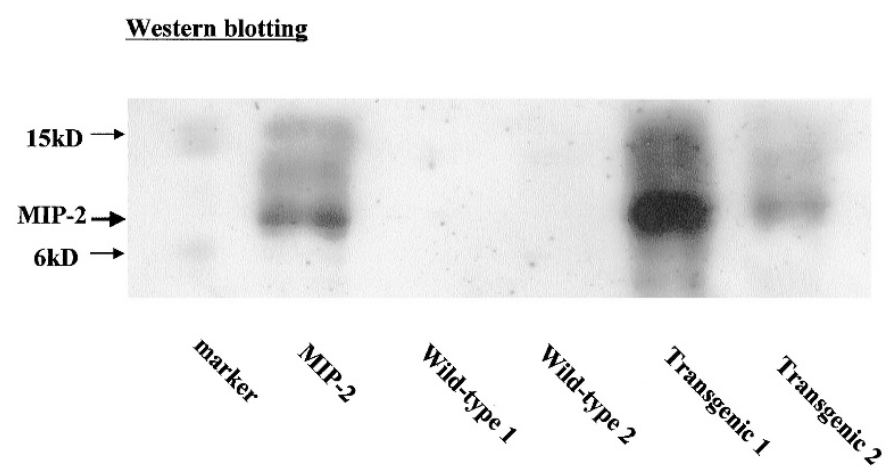

Figure 2. Cytoplasmic MIP-2 was detected by Western blot analysis. Cytoplasmic protein was extracted from wild-type and MIP-2 transgenic mice. MIP-2 was detected by a goat anti-mouse MIP-2 antibody. Mouse recombinant MIP-2 was used as a positive control. Results are representative of three independent experiments.
MIP-2 transgenic mice (25), both in the small intestine (Fig. 3, upper panels) and colon (Fig. 4, upper panels), when examined histologically or by quantitating total MPO activity per unit weight (Fig. 5).

DSS administered in drinking water is known to reproducibly induce mild intestinal inflammation with ulceration in mice $(17,18)$. To study whether epithelial expression of a chemokine increases neutrophil recruitment under conditions in which intestinal inflammation is triggered by other stimuli, DSS was administered in drinking water to wild-type and MIP-2 transgenic mice. A concentration of $2.5 \%$ DSS was chosen because it did not cause bloody diarrhea either in wild-type or MIP-2 transgenic mice, because blood can enhance the total MPO activity irregularly. This concentration was sufficient to induce neutrophil invasion into the intestine.

In wild-type mice, DSS induced a mild increase of neutrophil migration, observed in the intestine by histologic analysis. However, secretion by the epithelial cells of MIP-2 in transgenic mice reproducibly increased the intestinal inflammation induced by DSS treatment both in the small intestine (Fig. 3, lower panels) and the colon (Fig. 4, lower panels).

These findings were confirmed quantitatively by measuring total MPO activity in the whole small intestine and colon. The total MPO activity was significantly elevated after DSS treat-

\section{Wild-type}

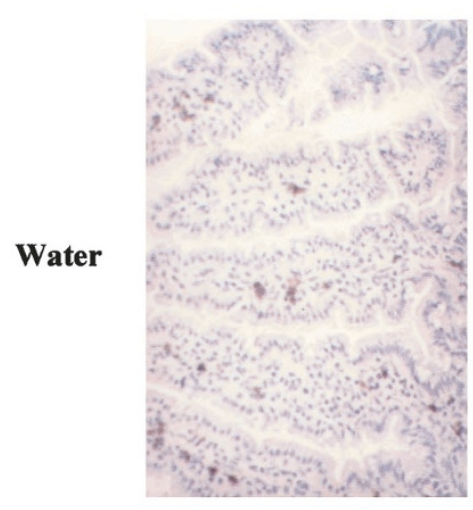

DSS

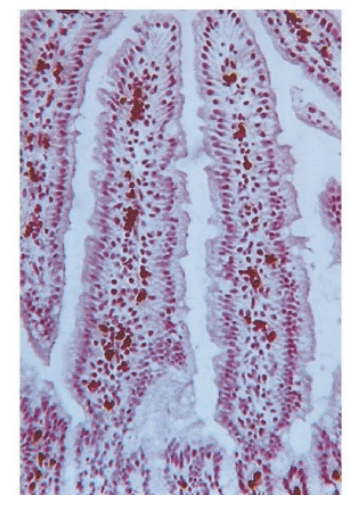

MIP-2 Transgenic
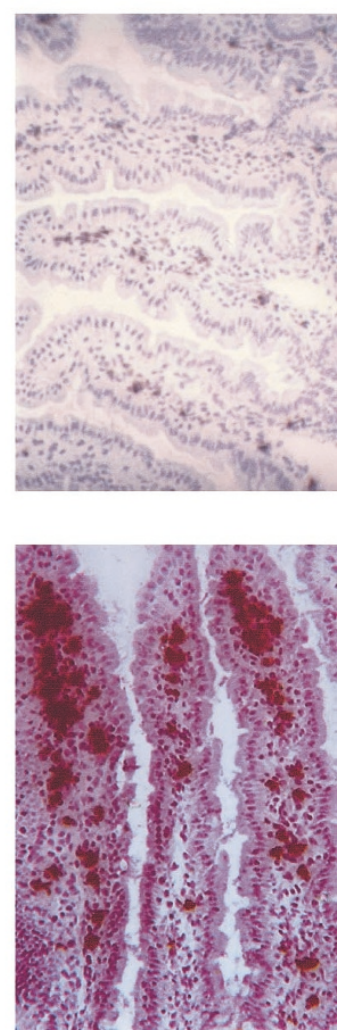

Figure 3. Neutrophil recruitment in the small intestine from wild-type and MIP-2 transgenic mice with or without $2.5 \%$ DSS treatment. Neutrophil recruitment was greater in MIP-2 transgenic mice than in wild-type mice after DSS treatment. Neutrophils were stained by MPO using the Hanker Yates reaction. Magnification $\times 100$. 
Wild-type
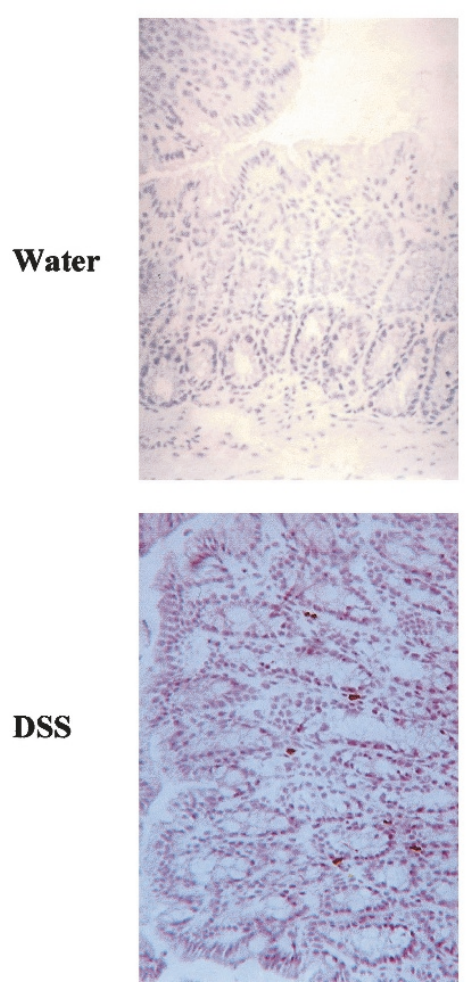

MIP-2 Transgenic
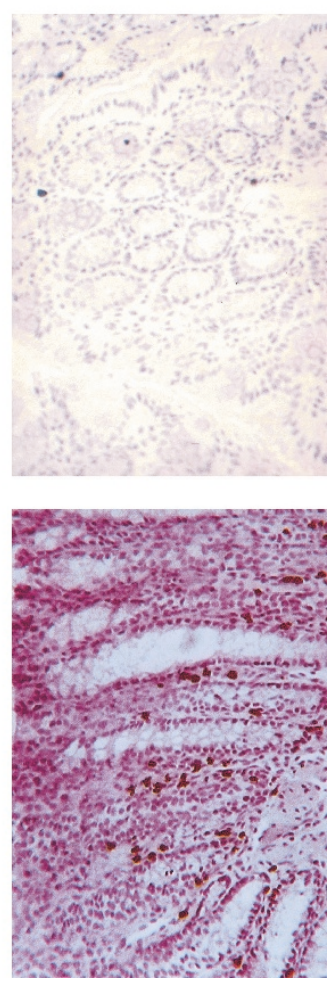

Figure 4. Neutrophil recruitment in the colon from wild-type and MIP-2 transgenic mice with or without $2.5 \%$ DSS treatment. Neutrophil recruitment was greater in MIP-2 transgenic mice than in wild-type mice after DSS treatment. Neutrophils in the colon were stained by MPO using the Hanker Yates reaction. Magnification $\times 100$.

ment in the wild-type mice both in the small intestine and colon $(p<0.01)$. Thus, the elevation of total MPO activity after DSS treatment was much greater in the MIP-2 transgenic mice both in the small intestine and colon $(p<0.01$; Fig. 5).

\section{DISCUSSION}

The increased infiltration of neutrophils and lymphocytes into the gastrointestinal tract is a hallmark of both ulcerative colitis and Crohn's disease. However, the contribution of epithelial cell chemokine secretion to the observed inflammatory changes has never been studied in a model of IBD. In this study we used the epithelial-specific expression of MIP-2 in transgenic mice to examine the hypothesis that chemokines secreted by the epithelium combine with the inflammatory processes generated in IBD. We used DSS treatment as a model of IBD, as it has been well validated and is reproducible. We have shown that the expression of even one chemokine by the epithelial cell doubled the neutrophil recruitment into the lamina propria of both colon and small intestine, suggesting that the epithelial cell chemokine secretion may multiply the effect of other inflammatory stimuli in the intestine.

Although the action of DSS is not completely understood, it appears to be phagocytosed by macrophages. These macrophages have enlarged lysosomes and contain a polysaccharide sulfate that may reduce phagocytic activity (17). In addition, DSS causes a change in the intestinal microflora, and particu-
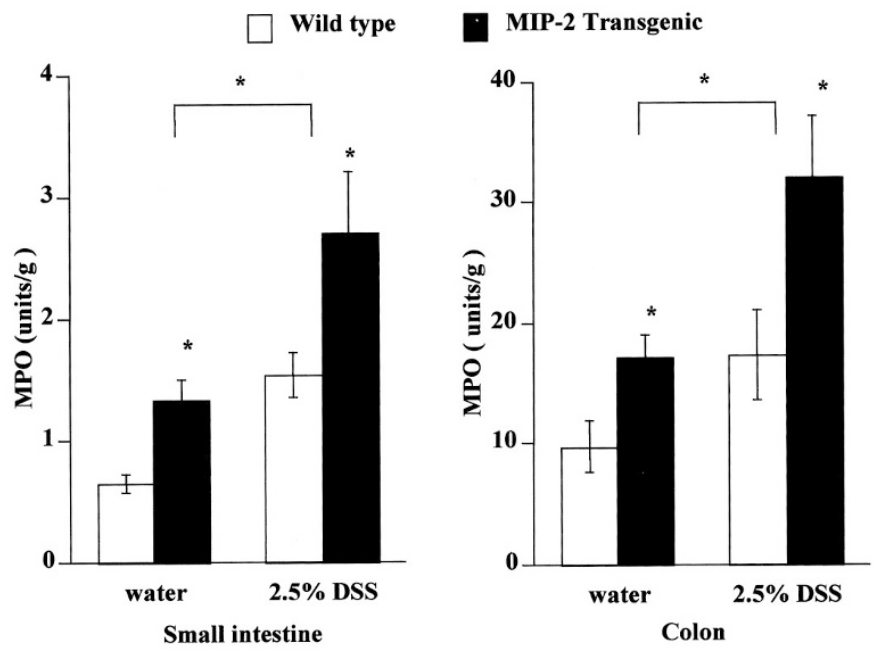

Figure 5. Neutrophil recruitment was much greater in MIP-2 transgenic mice than in wild-type mice both in the small intestine and colon after $2.5 \%$ DSS treatment. Neutrophil recruitment was demonstrated by total MPO activity. MPO was extracted from the whole small intestine and colon with $0.5 \%$ hexadecyltrimethylammonium bromide. Open columns show total MPO activity per unit weight of tissue derived from wild-type mice, and closed columns show those of MIP-2 transgenic mice. Data are presented as the mean $\pm \mathrm{SD}$ of eight animals for each group. ${ }^{*} p<0.01$.

larly an increase in the number of Gram-negative anaerobes (17). DSS may also be cytotoxic to epithelial cells and IEL, and may interfere with the normal interaction between intestinal lymphocytes, epithelial cells, and extracellular matrix (29). Treatment with DSS is therefore a good animal model for intestinal inflammation. Although DSS is reported to have its main site of action in the large intestine (probably because of the distribution of macrophages), we found significant neutrophil recruitment in the small intestine after DSS treatment by measuring total MPO activity (Fig. 5). The lack of reports of DSS action in inducing small bowel inflammation is not easily explained. However, there have been no reports in which neutrophils have been examined by MPO activity with flushing of all blood components from the vasculature as a pretreatment. Thus the finding of the greatly increased neutrophil recruitment in MIP-2 transgenic mice, which may produce more MIP-2 in the small intestine than do wild-type mice (Fig. 5 ), suggests that chemokine production from the epithelium is an important mechanism of DSS-induced mucosal inflammation. DSS may therefore stimulate intestinal epithelial cells and enhance the chemokine secretion to further increase neutrophil invasion in these mice.

The present study provides evidence that down-regulating epithelial chemokine secretion would result in reduced inflammation, even when other mechanisms in the intestine have initiated it. Any treatment regimen that decreases chemokine secretion in the epithelial cell is likely to reduce inflammation in IBD. It is possible that certain antiinflammatory drugs or dietary regimens such as enteral diets act in this way as part of their mechanism of action (2).

\section{CONCLUSION}

In summary, this study supports the hypothesis that epithelial cell chemokine secretion alters the amount of inflammation 
in the intestine, even when this is induced by inflammatory processes in the intestinal lumen.

Acknowledgments. The authors thank Drs. E. Schmidt and P. Leder for the JvSV plasmid, and Dr. J. Gordon for Fabpi promoter.

\section{REFERENCES}

1. Sanderson IR, Walker WA 1999 Mucosal barrier: an overview. In: Ogra PL Mestecky J, Lamm ME, Strober W, Bienenstock J, McGhee JR (eds) Mucosal Immunology, 2nd ed. Academic Press, San Diego, CA, pp 5-17

2. Sanderson IR 1998 Dietary regulation of genes expressed in the developing intestinal epithelium. Am J Clin Nutr 68:999-1005

3. Hershberg RM, Cho DH, Youakim A, Bradley MB, Lee JS, Framson PE, Nepom GT 1998 Highly polarized HLA class II antigen processing and presentation by human intestinal epithelial cells. J Clin Invest 102:792-803

4. Sanderson IR, Ouellette AJ, Carter EA, Harmatz PR 1993 Ontogeny of Ia messenger RNA in the mouse small intestinal epithelium is modulated by age of weaning and diet. Gastroenterology 105:974-980

5. Sanderson IR, Ouellette AJ, Carter EA, Walker WA, Harmatz PR 1993 Differential regulation of B7 mRNA in enterocytes and lymphoid cells. Immunology 79:434-438

6. Telega GW, Baumgart DC, Carding SR 2000 Uptake and presentation of antigen to $\mathrm{T}$ cells by primary colonic epithelial cells in normal and diseased states. Gastroenterology 119:1548-1559

7. Watanabe M, Ueno Y, Yajima T, Iwao Y, Tsuchiya M, Ishikawa H, Asio S, Hibi T, Ishii H 1995 Interleukin 7 is produced by human intestinal epithelial cells and regulates the proliferation of intestinal mucosal lymphocytes. J Clin Invest 95:29452953

8. Eckmann L, Jung HC, Schurer-Maly C, Panja A, Morzycka-Wroblewska E, Kagnoff MF 1993 Differential cytokine expression by human intestinal epithelial cell lines: regulated expression of interleukin 8. Gastroenterology 105:1689-1697

9. McCormick BA, Parkos CA, Colgan SP, Carnes DK, Madara JL 1998 Apical secretion of a pathogen-elicited epithelial chemoattractant activity in response to surface colonization of intestinal epithelia by Salmonella typhimurium. J Immunol 160:455-466

10. Weinstein DL, O'Neill BL, Metcalf ES 1997 Salmonella typhi stimulation of human intestinal epithelial cells induces secretion of epithelial cell-derived interleukin-6. Infect Immun 65:395-404

11. Jung HC, Eckmann L, Yang SK, Panja A, Fierer J, Morzycka-Wroblewska E, Kagnoff MF 1995 A distinct array of proinflammatory cytokines is expressed in human colon epithelial cells in response to bacterial invasion. J Clin Invest 95:55-65

12. Crowe SE, Alvarez L, Dytoc M, Hunt RH, Muller M, Sherman P, Patel J, Jin Y, Erns PB 1995 Expression of interleukin 8 and CD54 by human gastric epithelium after Helicobacter pylori infection in vitro. Gastroenterology 108:65-74

13. Ohno Y, Lee J, Fusunyan RD, MacDermott RP, Sanderson IR 1997 Macrophage inflammatory protein-2: chromosomal regulation in rat small intestinal epithelial cells. Proc Natl Acad Sci USA 94:10279-10284
14. Fusunyan RD, Quinn JJ, Ohno Y, MacDermott RP, Sanderson IR 1998 Butyrate enhances interleukin (IL)- 8 secretion by intestinal epithelial cells in response to IL-1 $\beta$ and lipopolysaccharide. Pediatr Res 43:84-90

15. O'Morain C, Segal AW, Levi AJ 1984 Elemental diet as primary treatment of acute Crohn's disease: a controlled trial. BMJ 23:1859-1862

16. Sanderson IR, Naik S 2000 Dietary regulation of intestinal gene expression. Annu Rev Nutr 20:311-338

17. Okayasu I, Hatakeyama S, Yamada M, Ohkusa T, Inagaki Y, Nakaya R 1990 A novel method in the induction of reliable experimental acute and chronic ulcerative colitis in mice. Gastroenterology 98:694-702

18. Mashimo H, Wu DC, Podolsky DK, Fishman MC 1996 Impaired defense of intestinal mucosa in mice lacking intestinal trefoil factor. Science 274:262-265

19. Wolpe SD, Sherry B, Juers D, Davatelis G, Yurt RW, Cerami A 1989 Identification and characterization of macrophage inflammatory protein 2. Proc Natl Acad Sci USA 86:612-616

20. Wolpe SD, Davatelis G, Sherry B, Beutler B, Hesse DG, Nguyen HT, Moldawer LL, Nathan CF, Lowry SF, Cerami A 1988 Macrophages secrete a novel heparin-binding protein with inflammatory and neutrophil chemokinetic properties. J Exp Med $167: 570-581$

21. Tekamp-Olson P, Gallegos C, Bauer D, McClain J, Sherry B, Fabre B, van Deventer S, Cerami A 1990 Cloning and characterization of cDNAs for murine macrophage inflammatory protein 2 and its human homologues. J Exp Med 172:911-919

22. Green RP, Cohn SM, Sacchettini JC, Jackson KE, Gordon JI 1992 The mouse intestinal fatty acid binding protein gene: nucleotide sequence, pattern of developmental and regional expression, and proposed structure of its protein product. DNA Cell Biol 11:31-41

23. Cohn SM, Simon TC, Roth KA, Birkenmeier EH, Gordon JI 1992 Use of transgenic mice to map cis-acting elements in the intestinal fatty acid binding protein gene (Fabpi) that control its cell lineage-specific and regional patterns of expression along the duodenal-colonic and crypt-villus axes of the gut epithelium. J Cell Biol 119:27-44

24. Simon TC, Roberts LJJ, Gordon JI 1995 A 20-nucleotide element in the intestinal fatty acid binding protein gene modulates its cell lineage-specific, differentiationdependent, and cephalocaudal patterns of expression in transgenic mice. Proc Natl Acad Sci USA 92:8685-8689

25. Ohtsuka Y, Lee J, Stamm DS, Sanderson IR 2001 MIP-2 secreted by epithelial cells increases neutrophil and lymphocyte recruitment in the mouse intestine. Gut 49:526533

26. Ohtsuka Y, Yamashiro Y, Maeda M, Oguchi S, Shimizu T, Nagata S, Yagita H, Yabuta K, Okumura K 1996 Food antigen activate intraepithelial and lamina propria lymphocytes in food-sensitive enteropathy in mice. Pediatr Res 39:862-866

27. Cicalese L, Caraceni P, Nalesnik MA, Borle AB, Schraut WH 1996 Oxygen free radical content and neutrophil infiltration are important determinants in mucosal injury after rat small bowel transplantation. Transplantation 62:161-166

28. Yamasaki Y, Matsuo Y, Zagorski J, Matsuura N, Onodera H, Itoyama Y, Kogure K 1997 New therapeutic possibility of blocking cytokine-induced neutrophil chemoattractant on transient ischemic brain damage in rats. Brain Res 759:103-111

29. Ni J, Chen S-F, Hollander D 1996 Effects of dextran sulphate sodium on intestinal epithelial cells and intestinal lymphocytes. Gut 39:234-241 